\title{
Estética y política: algunas propuestas novoseculares
}

\section{Aesthetics and Politics: Some New Century Proposals}

\author{
Rodrigo Montenegro \\ Centro de Letras Hispanoamericanas, Universidad Nacional de Mar del Plata. \\ Mar del Plata, Argentina. \\ rdmontenegro@gmail.com
}

\section{Resumen}

Propongo la lectura de algunos textos teóricos realizados durante la primera década del siglo xxi con la finalidad de cartografiar la compleja trama del saber estético y, al hacerlo, considerar nuevas flexiones y puntos de vista para leer las artes, la literatura y sus políticas. Las indagaciones de Rancière, Huyssen, Bourriaud, Laddaga y García Canclini se proyectan en el escenario contemporáneo como reformulaciones de un discurso que intenta referir el trabajo con la forma y la sensación y, al hacerlo, configuran una imaginación política. Se construye la visión de lo estético como una producción que reelabora las condiciones materiales y simbólicas del arte. En sus propuestas se realiza una caracterización singular de las estéticas contemporáneas en su potencialidad para poner en entredicho la rigidez disciplinar.

Palabras clave: teoría, estética, novosecular, política.

\begin{abstract}
I propose a reading of some theoretical-critical texts published during the first decade of the twenty-first century, in order to perform a cartography of the complex weft of aesthetic knowledge and, in doing so, to consider new inflections and points of view to read the arts, the literature and its policies. The inquiries of Jacques Rancière, Andreas Huyssen, Nicolás Bourriaud, Reinaldo Laddaga and Néstor García Canclini are projected on the contemporary scene as reformulations of a discourse that tries to refer the work with form and sensation, now disseminated as a production that reorganizes the material and symbolic conditions of art in its dialogue with the world. Each of these authors make a unique characterization of contemporary aesthetics, all of which question the modern disciplinary rigidity to identify aesthetic practices as acts that can reorganize the sense of community and the ways of life through sensible exploration.
\end{abstract}

Keywords: theory, aesthetics, new century, politics. 


\section{Introducción}

El interés por las potencias críticas o disensuales de las prácticas estéticas parece encontrar un renovado punto de partida durante los primeros años del nuevo siglo, tanto en la academia europea o norteamericana como en Latinoamérica. En este sentido, es posible cartografiar una serie de propuestas teórico-críticas que reevalúan los alcances e implicancias de la compleja trama del saber estético; y, al hacerlo, considerar las nuevas reflexiones y puntos de vista para leer las artes, la literatura y sus políticas. Luego de dos siglos, las indagaciones de Jacques Rancière, Andreas Huyssen, Nicolás Bourriaud, Reinaldo Laddaga o Néstor García Canclini se proyectan como reformulaciones de esa insistente palabra que intenta referir el trabajo con la forma y la sensación, ahora diseminada como un tipo singular de producción que reorganiza las condiciones materiales y simbólicas del presente. Uno de los puntos de contacto que agrupa a estas intervenciones críticas es la persistencia -incluso, la necesidaden fracturar cualquier idea o pretensión de especificidad para las consideraciones contemporáneas sobre esta esquiva práctica de pensamiento que, desde finales del siglo XVIII, compuso una trama de escrituras, lecturas y experiencias.

Desde posiciones singulares, y sin rehuir la polémica, estos ensayistas vuelven a indagar el régimen de inteligibilidad propuesto por la estética y, al hacerlo, demarcan las mutaciones de las prácticas artísticas durante la primera década del siglo xxi. El carácter común de sus propuestas se encuentra en el planteo historizado y coyuntural no solo de los sujetos y sus prácticas, sino del propio saber involucrado e identificado como aisthesis, alejándose, por lo tanto, del carácter estrictamente disciplinar orientado hacia la especulación filosófica. En su lugar, lo estético se construye como un pensamiento sobre la sensación, un territorio de exploraciones que reúne simultáneamente la praxis artística junto con los relatos críticos que producen su visibilidad, para finalmente expandir la esfera del arte hacia las relaciones y los modos de la comunidad. Podría arriesgarse como hipótesis que estas consideraciones novoseculares de la estética se yuxtaponen, una vez más, con la práctica política tal como la imaginaran las vanguardias históricas de principios del xx, especialmente en la teorización de Walter Benjamin; ${ }^{1}$

1 La elaboración de Walter Benjamin expuesta en su trabajo "El autor como productor" (1934) cristaliza el momento paradigmático de la reflexión estética en el período de vanguardias. La conferencia, dictada en el Instituto para el Estudio del Fascismo de París, puede ser considerada como una formulación teórica y, al mismo tiempo, el despliegue de una política cultural, dado que sus tesis se encuentran imbuidas de beligerancia política. Allí, Benjamin sostenía la necesidad de llevar a cabo una revisión revolucionaria de las técnicas del arte y convocar, de este modo, una alianza entre vanguardia política y vanguardia en la técnica de producción artística. Para el crítico, se imponía una figura de autor involucrado como trabajador revolucionario; un trabajador que mediante su intervención transformaba los medios de producción artística tradicionales de la sociedad burguesa. En efecto, según su consideración no alcanzaba con adoptar una "tendencia" al modo de la cultura oficial soviética, sino que era necesario disponer una revolución en los medios de producción del arte. Al recuperar la figura del poeta surrealista Louis Aragon, Benjamin configuraba la imagen del artista como un traidor a su propia clase: "Esa traición consiste en el escritor en un comportamiento que de proveedor de un aparato de producción le convierte en un ingeniero que ve su tarea en acomodar dicho aparato a las finalidades de la revolución proletaria" (134). En efecto, la imagen del escritor como un ingeniero que revisa y transforma su técnica consolida la imaginación crítica de Benjamin en su perfil vanguardista. Quizás no resulte menor advertir que, para Benjamin, autor, escritor y artista son significantes 
sin embargo, este regreso se efectúa con profundas revisiones que dejan a la vista una sinuosa genealogía crítica.

En sus ensayos, estos autores colocan a las artes en un régimen que debe ser actualizado y reordenado en diversos intervalos históricos, en distintas geografías y escalas de análisis. De hecho, uno de los puntos de interés se encuentra en calibrar y contrastar los pensamientos sobre la sensación que emergen desde la academia europea, junto con elaboraciones que enfocan la realidad de las experiencias latinoamericanas. Su carácter común se encuentra en la decidida oposición tanto a la herencia sacralizada de las bellas artes como a la mera politización de sus temas y miradas teóricas. Son estéticas heterodoxas que, aún reconociendo la historicidad disciplinar de sus problemas, se sitúan deliberadamente en la incomodidad del presente para reorganizar el arte moderno y contemporáneo. En este sentido, cabe preguntar qué dispositivos dan forma a la institución del arte en el debate actual. Probablemente sea imposible siquiera esbozar una imagen de las estéticas contemporáneas sin advertir las paradojas de un mundo atravesado por el fenómeno de la interconexión global que, sin embargo, restaura posiciones defensivas o conservadoras y no consigue articular la positividad de un enfoque culturalista o poscolonial. A esta consideración se suman las tensiones y asimetrías nunca resueltas del mercado del arte, involucrado en una dinámica errática de capitales simbólicos y financieros. Finalmente, la multiplicidad de medios técnicos obliga a considerar el carácter multimedial de las producciones artísticas, con lo cual se fractura, una y otra vez, cualquier intento de taxonomía. En suma, conectividad, mercado y diversidad técnica ingresan en la reflexión estética como significantes que deberían calibrarse en cualquier intento de producir una descripción, siquiera una especulación, sobre el arte y la literatura actuales.

\section{Algunas propuestas novoseculares}

Para considerar el panorama que intento cartografiar quizás sea pertinente advertir al menos dos rasgos que habilitan la lectura en serie de las propuestas. En ellas, la dimensión cifrada en el concepto "estética" intenta distinguirse frente a los discursos que operan desde una lógica de apropiación sobre los productos del arte para imponerles finalidades filosóficas, emancipatorias o interpretativas ajenas a las prácticas artísticas. Al mismo tiempo, se resisten a caer en una ilusión de especificidad que aísla esferas, funciones o procedimientos como salvaguarda para una definición sustancialista de los objetos del arte. A fin de precisar la productividad e historicidad del concepto, Jacques Rancière instala un punto de partida para su evaluación; un inicio que constituye en sí mismo una posición (crítica) de enunciación. De modo que el presente del arte y

correlativos, en cierto sentido, indistintos, todos los cuales resultan efectivamente depositarios de una visión teórica que yuxtapone la productividad estética y política como mecanismo para contrarrestar la estetización de la política. 
la estética es considerado por el autor en su carácter posutópico, es decir, contrastado con las pretensiones de las vanguardias históricas ${ }^{2}$ y las herencias del arte crítico desarrollado a lo largo del siglo xx. Por lo tanto, pensar (o repensar) qué es la estética constituye un trabajo de elaboración crítica que interpela la transformación histórica de las formas y experiencias sensibles; y, para hacerlo, compone escenas específicas de producción conectadas con la trama que posibilita su emergencia. Sin embargo, la historicidad materializada en los objetos del arte no puede ser concebida como una ordenada secuencia teleológica; lejos de organizarse como una mera sucesión de normas y rupturas formales, de restauraciones y transgresiones, la estética despliega una dinámica en la que intervienen temporalidades múltiples, incluso anacrónicas. La historicidad, entonces, se reintroduce como un factor capital de sentido, un componente transversal y constitutivo; dado que no existiría una estética (una literatura, una pintura, etc.) transhistórica.

Todo discurso sobre la forma y la sensación, según Rancière, se encuentra ligado a un pensamiento que es, en sí mismo, un dispositivo de visibilidad implicado en las constantes mutaciones de los escenarios culturales y teóricos. En El malestar en la estética, afirma: “Estética' no es el nombre de una disciplina: es el nombre de un régimen de identificación específica del arte. Los filósofos, a partir de Kant, tienen la tarea de pensar dicho régimen" (17). El desplazamiento que propone el filósofo radica en identificar y corregir una extensa tradición de la institución filosófica en todo lo que ella tiene de disciplinar. De acuerdo a su perspectiva, la estética se transforma en un régimen de identificación y visualización de las obras de arte, y es en este punto que su propuesta se opone tanto a las estéticas especulativas y a la tradición analítica, como a la inestética. ${ }^{3}$ Según Rancière, la aisthesis se despliega como una matriz de pensamiento, un saber crítico fundado en mecanismos perceptivos; un régimen que piensa los modos de la experiencia vinculada al mundo sensible y asociados a la praxis artística; régimen fundamentalmente involucrado con las formas que adopta la sensación y con las escenas que componen su vida histórica. El funcionamiento de este régimen se caracterizaría por la más absoluta desjerarquización de temas, materias y sujetos; un territorio en el cual se confunden y derivan objetos y prácticas sensibles, creando tiempos y espacios singulares, aunque en relación de continuidad con el mundo común. La frontera entre el arte y el mundo, así como la continuidad entre las experiencias estéticas y los relatos que permiten visualizarlos, nunca se percibió tan lábil y porosa. La radical posición de Rancière interpela especialmente a los

2 En su célebre Teoría de la vanguardia, Peter Bürger definió con precisión los movimientos históricos de vanguardia. El autor los sitúa en las primeras décadas del siglo xx y afirma que su principal característica es la ejecución de una crítica radical a la institución del arte para conducirlo hacia una nueva praxis vital. Por su parte, Andreas Huyssen advierte en Después de la gran división que la emergencia del concepto de vanguardia política en el pensamiento de los socialistas utópicos se configura a mediados del siglo xix, cuando el arte moderno alcanza su plena autonomía, al menos en el campo intelectual europeo.

3 Rancière debate la lectura de Alain Badiou, sobre todo por el carácter neoplatónico y ontológico de sus planteos elaborados, principalmente, en Pequeño manual de inestética. 
discursos críticos que abordan la productividad estética, pues, según su perspectiva, no existiría una separación tajante entre una inteligencia activa proyectada sobre una materia pasiva, sino que ambas participarían de una misma indeterminación. A partir del desarreglo de las jerarquías, la destrucción de todo principio de verosimilitud naturalizada y la pasiva solidaridad de las formas del arte con los modos de representación de la vida pública, la estética se convierte en "el pensamiento del nuevo desorden" (23), un conjunto de producciones sensibles que habilitan la mezcla sin subordinaciones de temas, lenguajes e identidades. Esta productividad desjerarquizada de lo estético constituye el núcleo de su política en tanto exploración de las formas de vida por venir.

Por lo tanto, para Rancière la estética no puede ser pensada por fuera de su dimensión política, aunque esta debe ser entendida en un sentido específico: no como lucha por el poder o su ejercicio, sino como un modo de participación en los espacios de la vida en común, una creación de experiencias y subjetividades nunca completamente clausuradas por una maquinaria institucional. ${ }^{4}$ La práctica estética comparte esta apertura hacia el espacio común, ella misma se involucra en la producción de objetos e identidades proyectadas hacia una escena necesariamente compartida por otras esferas y racionalidades. En este sentido, estética y política se encuentran imbricadas en tanto regímenes de imaginación y producción; ambas constituyen dispositivos de pensamiento a partir de los cuales se hacen visibles los sujetos y sus experiencias, sus lenguajes y los materiales que emergen desde su actividad creadora. ${ }^{5}$ Por lo tanto, constitutiva e históricamente, la estética nunca habría abandonado la querella sobre las potencialidades políticas del arte, dado que esta ineludible dimensión se involucra con los debates que unen (o dividen) a los seres parlantes en su vida en comunidad. Tanto las políticas del arte, como la estética en tanto reflexión crítica, se constituyeron desde los albores del romanticismo como la toma de posesión de un tiempo propio, considerado como un tipo particular de suspensión, aunque vinculado dialógicamente con el mundo. Al instalarse en un mismo plano junto a las formas ordinarias de la experiencia (triviales, fetichistas, etc.), el régimen de producción de las artes reordena las condiciones impuestas por la lógica de la dominación y, a través de su política inmanente, compone un lenguaje sobre las formas sensibles para arrancar una experiencia específica, divergente, heterónoma.

4 Sostiene Rancière: "La política, en efecto, no es el ejercicio del poder y la lucha por el poder. Es la configuración de un espacio específico, el recorte de una esfera particular de experiencia, de objetos planteados como comunes y como dependientes de una decisión común, de sujetos reconocidos como capaces de designar estos objetos y de argumentar sobre ellos" (El malestar en la estética 33).

5 Argumenta Rancière: "Aquello que el singular del 'arte' designa es el recorte de un espacio de presentación por el cual las cosas del arte son identificadas como tales. Y aquello que liga la práctica del arte a la cuestión de lo común es la constitución, a la vez material y simbólica, de un cierto espacio-tiempo, de una suspensión en relación con las formas ordinarias de la experiencia sensible. El arte no es político, en primer lugar, por los mensajes y los sentimientos que transmite acerca del orden del mundo. No es político, tampoco, por la manera en que representa las estructuras de la sociedad, los conflictos o las identidades de los grupos sociales. Es político por la misma distancia que toma respecto a sus funciones, por la clase de tiempos y de espacio que instituye, por la manera en que recorta este tiempo y puebla este espacio" (El malestar en la estética 33). 
La estética de Rancière puede ser definida como un pensamiento sobre las formas sensibles y sus modos disensuales de operar en un tejido socio-semiótico compartido junto a la lógica del poder y la mercantilización. Aun así, Rancière reconoce claramente la necesidad de profundizar las diferencias y malentendidos en torno de la dimensión política del arte. En efecto, su propuesta se distancia tanto de la antigua ortodoxia marxista como del arte engagée; tampoco busca implicar a las prácticas artísticas en una lectura sociológica, interpretativa de los estados de dominación políticoeconómica, o reclamar una politización del artista a partir de disputas particulares. El pensamiento de Rancière encuentra lo político como un mecanismo inherente de lo estético a partir de la creación de experiencias, sujetos y objetos que se sustraen a sus funciones (ordinarias, frecuentes, preestablecidas, etc.) en una suspensión ${ }^{6}$ propia del régimen de las artes. En este sentido, la literatura y el arte se implicarían en la creación de un tiempo y un espacio que suspende las condiciones habituales de producción y poder, para instituir un espacio solo definible por ese recorte en un nuevo "reparto de lo sensible". Es en ese punto crucial en el cual estética y política se cruzan como modos de intervenir y entender ese reparto; ambos regímenes se convierten en dispositivos de identificación y visibilidad que distribuyen la identidad de los sujetos y los objetos de la política o del arte, en cada caso. Por lo tanto, el desarrollo teórico de Rancière convierte a la estética en una metapolítica, una actividad que recorta material y simbólicamente territorios y temporalidades, voces y objetos,

6 La noción de "suspensión" como dispositivo teórico que intenta describir el valor y la experiencia estética o la escritura literaria aparece formulada, con ciertos matices descriptivos, por Roland Barthes en El placer del texto. Tanto en Barthes como en Rancière resulta evidente el diálogo, aunque velado, con la tradición filosófica desde el pensamiento griego -especialmente en la Nueva Academia y los filósofos escépticos-, el idealismo romántico, hasta la fenomenología de Husserl, en la cual la epojé se constituye como una actitud -una suspensión del juicio, un estado de reposo- frente al problema gnoseológico (Ferrater Mora). En su teoría del texto vinculada a la figura psicoanalítica del placer, Barthes sostiene: "No se puede decir nunca de manera suficiente la fuerza de suspensión del placer: es una verdadera epojé, una detención que fija desde lejos todos los valores admitidos (admitidos por sí mismos). El placer es un neutro [...] El placer del texto es eso: el valor llevado al rango suntuoso de significante" (86). Por su parte, Jacques Rancière recorre el principio histórico de esta "suspensión" para encontrar su antecedente en la estética de Schiller, a partir de la cual deriva un sentido específico hacia las obras de arte que incluye necesariamente la literatura: "aquello que liga la práctica del arte a la cuestión de lo común es la constitución, a la vez material y simbólica, de un cierto espacio-tiempo, de una suspensión en relación con las formas ordinarias de la experiencia sensible" (El malestar en la estética 33).

7 Rancière define su dispositivo conceptual en El reparto de lo sensible a partir del diálogo polémico con el pensamiento político/poético clásico-aristotélico, así como desde una reactualización de las perspectivas de Benjamin: "Llamo reparto de lo sensible a ese sistema de evidencias sensibles que al mismo tiempo hace visible la existencia de un común y los recortes que allí definen los lugares y las partes respectivas. Un reparto de lo sensible fija entonces, al mismo tiempo, un común repartido y partes exclusivas. Esta repartición de partes y de lugares se funda en un reparto de espacios, de tiempos y de formas de actividad que determina la manera misma en que un común se ofrece a la participación y donde los unos y los otros tienen parte en este reparto. El ciudadano, dice Aristóteles, es aquel que tiene parte en el hecho de gobernar y de ser gobernado. Pero otra forma de reparto precede a este tener parte: aquel que determina a los que tienen parte en él. El animal hablante, dice Aristóteles, es un animal político. Pero el esclavo, si es que comprende el lenguaje, no lo 'posee'. Los artesanos, dice Platón, no pueden ocuparse de cosas comunes porque no tienen el tiempo de dedicarse a otra cosa que su trabajo. No pueden estar en otro sitio porque el trabajo no espera. El reparto de lo sensible hace ver quién puede tener parte en lo común en función de lo que hace, del tiempo y el espacio en los cuales esta actividad se ejerce. Tener tal o cual 'ocupación' define competencias o incompetencias respecto a lo común [...] Hay entonces, en la base de la política, una 'estética' que no tiene nada que ver con esta 'estetización de la política’ propia de la 'época de masas', de la cual habla Benjamin [...] Es un recorte de tiempos y de espacios, de lo visible y de lo invisible, de la palabra y del ruido que define a la vez el lugar y la problemática de la política como forma de experiencia" (9-10). 
prácticas y teorías. A partir de la potencia crítica e imaginativa de sus creaciones, lo estético suspende la funcionalidad ordinaria del material sensible, agita los escenarios sociales y contradice la lógica del poder para proponerse como desacuerdo. De esta forma, el régimen estético rancièriano constituye una matriz perceptiva e intelectual que reemplaza la legislación mimético-aristotélica -es decir, la doxa que cristaliza efectos de representación al interior del arte-, y en su lugar hace visible la ausencia total de jerarquías, legislaciones preestablecidas o naturalizadas. Rancière busca hacer inteligible el panorama de las condiciones materiales e históricas de la producción del arte moderno; su discusión parte de un desajuste irreconciliable entre la poiesis -como forma de hacer- y la aisthesis -como forma de ser-:

De Kant a Adorno, pasando por Schiller, Hegel, Schopenhauer o Nietzsche, el discurso estético no tendrá otro objeto que la idea de esa relación discordante. Y lo que se dispondrá a enunciar, entonces, no es la fantasía de mentes especulativas: es el régimen nuevo y paradójico de identificación de las cosas artísticas. A ese régimen es que he propuesto llamarlo "régimen estético del arte" (El malestar en la estética 17).

La definición de Rancière reconoce y opera sobre esa tradición filosófica, en la cual la estética modula nuevas modalidades del ser; aún a riesgo de caer en una ontología estética, la propuesta es observar el devenir histórico y de las formas sensibles. Se impone, por lo tanto, la consideración coyuntural de la estética en el discurso moderno y su emergencia como consecuencia del pensamiento crítico del siglo xviII, para luego apuntalar la revolución romántica. La irrupción de la modernidad estética sitúa el momento histórico cuando el arte de escribir deja atrás el orden de las Bellas Letras y se transforma en literatura. Pero sobre todo, marca el inicio de un pensamiento que aborda el problema de la sensación sin garantías finales de sentido, sin relaciones de proporción y verosimilitud a priori. Solo a través de una paradójica dialéctica inconclusa, el régimen de las artes realiza su dinámica productividad crítica.

Ahora bien, es innegable que la operación crítica de Rancière establece un diálogo polémico con la gran teoría estética del siglo xx. Adorno es el nombre propio que formula, quizás en su mayor potencia, los alcances del pensamiento estético moderno, y es en gran medida, junto con Walter Benajmin, el interlocutor implícito de las problematizaciones elaboradas por Rancière. La relación dialéctica entre autonomía y heteronomía, ${ }^{8}$ considerada por el filósofo frankfurtiano en su Teoría

8 La valoración de la autonomía artística constituye el punto nodal de la Teoría estética de Adorno, eje que sustenta su vinculación negativa con las formas de administración de la industria cultural. Sostiene Adorno: "La posición de los artistas en la sociedad, tras la época de la autonomía artística, tiende a acercarse de nuevo a lo heterónomo. La Revolución Francesa prestó servicios a los artistas, pero los convirtió en sus entertainers. [...] La desaparición de la distancia entre el artista como sujeto estético y como persona empírica prueba también que ha quedado absorbida la distancia entre arte y realidad empírica sin que el arte haya penetrado en esa vida libe que no existe" (330). Por lo tanto, para Adorno el carácter político del arte, o más precisamente "la relación entre praxis social y arte" (331), se aleja de la politización de sus temas, tal como lo demuestra su rechazo al realismo socialista, y se propone como pura 
estética, es replanteada para validar el carácter heterónomo e impropio de la estética en su relación disensual con las formas dominantes de la experiencia sensible. Si la estética se presenta para Rancière como el pensamiento del desorden inespecífico, esto se debe a la irreductible heteronomía de sus lenguajes y formas. Se contradice, entonces, la tradición teórica que ve en la literatura y el arte modernos el hallazgo de la especificidad; sostiene Rancière en La palabra muda: "No hay lengua propia de la literatura, solo una sintaxis que primero es un orden de la visión, es decir un desorden de la representación" (143). Su reformulación crítica entiende que la obra no se produce a través de un lenguaje artificioso que, sustraído al mundo, opera en radical negatividad la restauración de un sentido imposible para la vida alienada. Por el contrario, lo que las artes proponen es, paradójicamente, su impropiedad; una modulación de la materia sensible que ha quebrado la adecuación entre los modos de ser y su expresión. En consecuencia, el problema del pensamiento estético es sostener y comprender las tensiones de esa modulación entre lo propio del arte y su disolución en el mundo común; entre las formas liberadas a la proliferación de sentidos y su diálogo con las lógicas de la apropiación y la administración interpretativa. En consecuencia, el malestar en la estética contemporánea sería consecuencia de la paradoja constitutiva descrita por Adorno entre autonomía y heteronomía, entre la negatividad y su dispersión. Frente a este panorama, Rancière despliega una estética heterónoma que entiende el arte y la literatura como formas disensuales de expresión sensible. En este contexto, las políticas de la estética-desde los experimentos modernos a las prácticas contemporáneas- reinscriben la potencia crítica del desacuerdo para restaurar, a cada paso de la historia, la posibilidad de crear nuevas formas, leguajes y voces.

Por su parte, Nicolás Bourriaud coloca plenamente el centro de su propuesta crítica en el carácter social de las prácticas artísticas. En su trabajo, Estética relacional (2008), busca la configuración de una estética que, si bien se muestra atenta al juego de las formas, subraya especialmente la contingencia histórica y coyuntural de sus modalidades y funciones, las cuales "evolucionan según las épocas y los contextos sociales, y no tiene una esencia inmutable" (9). A partir de esta perspectiva profundamente antiesencialista, incluso antiformalista, Bourriaud interpela directamente a la teoría estética como marco crítico desde el cual abordar las producciones del arte y su emplazamiento en el mundo, con el objetivo de considerar los canales a través de los cuales el arte expande y dispersa sus efectos fuera de su campo disciplinar. Según Bourriaud, el crítico no puede sino estudiar la estética desde su presente, situado y atravesado por una red de sensibilidades y afectos que, en última instancia, condicionan e incluso anulan cualquier pretensión de distancia crítica. Esta valoración de la subjetividad implica la composición de racionalidades críticas necesariamente circunstanciales. En este sentido, la práctica teórica de la estética relacional se coloca

negatividad: "El arte, al negar y superar la realidad empírica, concreta la referencia a esa realdad negada y superada, y este hecho constituye la unidad de su criterio estético y social y adquiere así una cierta prerrogativa” (333). 
en el mismo plano de composición junto a los productos y experiencias del arte, aunque tensionando temporalidades diversas y accionando registros de conectividad que interactúan para expandir las posibilidades de la conversación estética.

Para Bourriaud, la obra de arte se plantea como una territorialidad fundamentalmente social, y es a través de esta consideración que se efectúa el carácter distintivo de su propuesta: "La posibilidad de un arte relacional -un arte que tomaría como horizonte teórico la esfera de las interacciones humanas y su contexto social, más que la afirmación de un espacio simbólico autónomo y privado- da cuenta de un cambio radical de los objetivos estéticos, culturales y políticos puestos en juego por el arte moderno" (13). El pensamiento de Bourriaud lleva al extremo el carácter intersubjetivo de los productos del arte, para inscribirse en una tradición abiertamente materialista que niega cualquier posibilidad de definir una estética a través de procedimientos inmanentes. En este sentido, su afirmación es contundente: "el arte siempre ha sido relacional en diferentes grados" (14). En efecto, su propuesta erradica todo substancialismo de las prácticas artísticas para señalar a la trama social que efectúa su posibilidad de emergencia y visibilidad como el único componente verdaderamente transhistórico. En definitiva, el punto extremo de la apuesta de Bourriaud conduce a un vaciamiento de la noción de obra para encontrar, en su lugar, una productividad de la experiencia artística vinculada a una multiplicidad de efectos interpersonales.

Una revisión pormenorizada de las condiciones y mutaciones de la estética contemporánea aparece desarrollada en los ensayos de Reinaldo Laddaga Estética de la emergencia: la formación de otra cultura de las artes (2006) y Espectáculos de realidad (2007), textos que recogen abiertamente la preocupación por el agotamiento de las prácticas asociadas a las artes y la literatura durante las últimas décadas. En principio, resulta interesante señalar en los trabajos de Laddaga la construcción de cierta perspectiva panorámica; el crítico argentino produce su indagación desde la academia norteamericana, aunque ocupándose de objetos culturales disímiles y geográficamente distantes (desde Vyborg a Buenos Aires). Sin duda, la amplitud del enfoque responde a una decisión teórica, esto es, leer experiencias estéticas fuertemente locales sin perder de foco su proyección en la escena global. Igualmente, según Laddaga, ambos ensayos forman parte de un mismo proyecto que oscila entre las distintas formas del arte colaborativo, en un caso, y la narrativa latinoamericana, en otro. En este sentido, observar el presente del arte y la literatura latinoamericana adquiere una relevancia primordial que actúa como contraste o intervalo singular frente a la tradición de una modernidad estética enclaustrada en la cultura europea. Los ensayos de Laddaga subvierten el ordenamiento centro-periferia para recorrer una superficie global multifocal, observando la singularidad de cada hecho estético en relación específica con su espacio local de emergencia.

A partir de ciertos signos de obsolescencia registrados en el paradigma moderno y cristalizados en el dogma estético del modernismo, Estética de la emergencia busca componer los rasgos de una nueva escena iniciada durante las últimas décadas del 
siglo xx. Esta transformación diseñaría un régimen que Laddaga designa como un cambio en la "cultura de las artes" (22). Su movimiento de lectura involucra una perspectiva explícitamente heredera de la "ontología del presente" trazada por Michel Foucault en ¿Qué es la Ilustración?, entendida como práctica crítica, actitud y ethos filosófico. En este sentido, la propuesta de Laddaga consiste en revisar la mutación de las artes y la literatura en el paso hacia el nuevo siglo a partir de objetos y experiencias impensadas en las fronteras de la modernidad, incluso franqueando los debates en torno a la condición posmoderna característica de los modelos teóricos dominantes durante las décadas de los ochenta y los noventa.

La nueva cultura de las artes postula un régimen de sentido e identificación que no puede ser delimitado por las formas establecidas en la tradición moderna y sus modos de organización disciplinaria. La redefinición del ámbito de la cultura -una cultura visualizada como patchwork- es propuesta por Laddaga a partir del cruce entre los aportes teóricos de Rancière y la perspectiva histórica de inspiración foucaultiana. Con ello, la idea del "régimen estético de las artes", que en Rancière describe el ámbito de la creación artística desde el siglo XVIII, se solapa con una radical preocupación por el presente del nuevo siglo xxi en su plena dimensión histórica: “un régimen es un vínculo entre modos de producción, formas de visibilidad y modos de conceptualización que se articula con las formas de actividad, organización y saber que tienen lugar en un universo histórico determinado" (Laddaga, Estética de la emergencia 33). En consecuencia, la rígida estructura disciplinar que ordenó el saber, dispuso los modos de la discusión y codificó las formas de práctica estética constituye una compleja red que se dispersa en el escenario contemporáneo. La pregunta, entonces, es cómo leer las prácticas de escritura colaborativa cuyo soporte se encuentra en la virtualidad; cómo registrar acciones reales de apropiación y transformación del espacio público a través de las tecnologías de la ficción; cómo dimensionar el borramiento del límite entre artistas, críticos, productores y consumidores; cómo realizar una apropiación crítica de la historia a través de los nuevos lenguajes audiovisuales. En definitiva, dispersión y mutación serían las claves para el replanteo de las artes en un escenario cultural intervenido por las repetidas crisis del capitalismo industrial, las transformaciones de los estados nacionales y una paradójica visión global que, de acuerdo con Laddaga, resquebraja las garantías de una episteme en declive. El problema radica en encontrar los modos para hacer pensable un nuevo ciclo cultural que recorre distintas geografías - muchas de ellas, con radicales asimetrías socioeconómicas- e intenta renovar las formas y problemas estéticos superando el posmodernismo y su vocación multicultural; especialmente cuando parecen aflorar tanto en Europa como en América nuevas modalidades culturales defensivas y conservadoras como basamento identitario de los estados.

A partir de este panorama, Laddaga describe la producción artística y literaria como una herramienta de exploración sobre las "insuficiencias y potencialidades de la vida común en un mundo histórico determinado" (Estética de la emergencia 8); 
entre ellas, las nuevas “ecologías culturales" (42) efectúan una intervención simbólica y material realizada en distintos proyectos de arte colaborativo. Los objetos culturales que señalan esta mutación se encuentran en la fundación de editoriales o revistas, las múltiples formas de arte colectivo, las intervenciones sobre el espacio urbano y el despliegue multimedial de recursos técnico-artísticos cuya infraestructura de base se encuentra en la amplia difusión de Internet. Estos modos de operación cultural vuelven a postular hipótesis sobre las relaciones estéticas, políticas y experienciales que unas subjetividades mantienen con sus entornos, cada vez más ampliados y abiertos a la posibilidad de articular una dialéctica global-local. La mirada crítica de Laddaga intenta cubrir y formar parte de ese proyecto que, en sí mismo, reordena las dimensiones de lo pensable al interior del régimen de las artes. El perfil constructivista de los proyectos artístico-culturales estudiados por el autor plantea la necesidad de articular una indagación entre la estética y "las condiciones de la vida social en el presente" (15). Este enfoque encuentra en los "modos posdiciplinarios" (19) de operación cultural formas caracterizadas por el cruce de lenguajes (la literatura y la red; la ficción y la arquitectura; la performance y la economía; el cine documental y la crítica a los medios), todas ellas experiencias híbridas de interdisciplina. Por supuesto, Laddaga advierte que este tipo de cultura artística reclama nuevas matrices de lectura, esto es, un nuevo tipo de crítica. La invención de nuevos imaginarios para la cultura de las artes revisa los compuestos antes llamados "obras", las subjetividades que intervienen en su creación, "autores", y las lecturas que sobre ellos se realizan como marcos de inteligibilidad o especulación crítica.

Ahora bien, en el umbral de estas transformaciones, Laddaga plantea una necesaria reformulación de la práctica crítica a fin de diferenciarla del crítico moderno, ocupado en decodificar y construir los sentidos del texto literario en la soledad de una lectura, o del observador silencioso de una obra en el museo. Estas escenas constituyen en sí mismas una separación reglada entre los que producen y los que consumen, entre la creación artística y la racionalidad crítica; según Laddaga, "el despliegue de esta actividad tiene como condición la supresión de otra: la actividad que consiste en realizar acciones orientadas a modificar estados de cosas inmediatos en el mundo" (Estética de la emergencia 37). Las formas contemporáneas del arte y la literatura indagarían críticamente esa separación, caracterizada en la escena típica de lectura o contemplación aurática, al dejar en segundo plano la visión del "autor retirado" (41) y del lector solitario que se vinculan a partir de un objeto designado como "obra".

Este interés por la redefinición de las artes verbales en el presente se concreta en el ensayo Espectáculos de realidad (2007). Allí, Laddaga despliega su visión sobre

9 Para Laddaga, no es casual que "nos encontremos, con cada vez mayor frecuencia, con individuos que, en nombre de la voluntad de explorar las relaciones entre la producción de textos o de imágenes y la vida de las comunidades, se obstinan en participar en la generación de pequeñas o vastas ecologías culturales donde la instancia de la observación silenciosa, a la vez que la distinción estricta entre productores y receptores, es reducida" (Estética de la emergencia 42). 
el escritor y, por ende, el crítico, quienes, en lugar de disponerse hacia "construcciones densas de lenguaje" (14), se presentan como "productores de espectáculos de realidad" (14). En este sentido, las operaciones conscientes con los restos de la modernidad literaria se orientan, ahora, a construir objetos inconclusos o al menos permiten observar su proceso de composición. La escritura de estos nuevos objetos contradice, paradójicamente, la genealogía material del artefacto-libro. La velocidad en su publicación y la aparente incorrección (César Aira y Mario Bellatin ofician como casos ejemplares) llevan a pensar en una nueva imagen del libro realizado por bloques imperfectos o irregulares; esto es, una literatura abierta a la improvisación, a las contingencias, a la multiplicidad de soportes, dado que lo verbal no siempre equivale a lo impreso. En definitiva, una literatura que según Laddaga "aspira a la condición mutante" (15) y que, por lo tanto, rebasa ampliamente la noción de "intertextualidad" -acuñada por Julia Kristeva en la década del sesenta como relectura de Mijaíl Bajtín- para proponer un nuevo régimen de lecturas, relaciones y producciones cada vez más amplio y heterónomo.

La ontología del presente que Laddaga recupera desde Foucault adquiere toda la potencia de una interrogación crítica, una "descripción, necesariamente incierta, de las líneas de fuga y de tensión que atraviesan el territorio en que desplegamos nuestras prácticas, configuramos nuestras acciones, extendemos nuestras relaciones, realizamos nuestras experiencias" (Espectáculos de realidad 23). En consecuencia, la estética de Laddaga se despliega abiertamente como un dispositivo de exploración; su capital interés por la emergencia valora, en todo sentido, la irrupción de lo improbable en el universo disciplinar de las artes. Sus procedimientos críticos adquieren el comportamiento de una cartografía sobre territorialidades específicas (locales), junto con la reflexión sobre la forma sensible. Esta yuxtaposición configura un pensamiento sobre las imágenes de una comunidad impensada en sus modalidades estético-políticas de sociabilidad y experimentación. En la insistencia en una estética de la emergencia -o de lo "emergente", pensando con Raymond Williams- radica el impulso por reordenar el mapa de las artes y sus sentidos.

Durante el año 2010 fueron publicados dos libros que extienden en una modulación afín el diálogo sobre las perspectivas estéticas contemporáneas: Modernismo después de la posmodernidad de Andreas Huyssen y La sociedad sin relato: antropología y estética de la inminencia de Néstor García Canclini, cuyo subtítulo adelanta el recorrido crítico propuesto. Estos ensayos formulan interrogantes sobre algunas nociones clave para el arte y la literatura actuales, al tiempo que revisan los itinerarios que la teoría crítica y la sociología produjeron a lo largo del siglo xx.

En el caso de Huyssen, la indagación expande y actualiza su trabajo de la década de los ochenta, Después de la gran división: modernismo, cultura de masas, posmodernismo; ensayo posicionado polémicamente contra los planteos binarios y reduccionistas que oponían modernismo y posmodernismo en una secuencia lineal de temporalidad histórica. Ya en ese texto, la lectura crítica sobre los medios masivos, 
su incidencia en la política y el mercado del arte formaban parte de sus objetos de análisis. Su revisión de la teoría estética adorniana, fundada en la distancia negativa hacia toda masificación de las industrias culturales, adquiere especial significación en una historia de las ideas del siglo xx, al ser identificada por Huyssen como la filosofía par excellence del alto modernismo. Su provocativa tesis advertía en el rechazo hacia la cultura massmediática -incluso descreyendo de las potencialidades revolucionarias de los medios técnicos, argumento claramente opuesto al de Walter Benjamin- un punto de contacto fundamental entre el pensador de la escuela de Frankfurt y la nouvelle critique francesa.

La propuesta de Huyssen para la primera década del siglo xxI, en Modernismo después de la posmodernidad, se plantea contra la cristalización de los estudios culturales de la academia norteamericana, donde él mismo desarrolla su trabajo, y al mismo tiempo como un intento por ampliar el alcance geográfico del modernismo. En cierto sentido, implica un regreso a una categoría de análisis previa al impasse en torno a los debates sobre el posmodernismo, aunque claramente este retorno adquiere valencias específicas. Al indagar en modernidades alternativas ${ }^{10}$ a la europea y norteamericana, en un presente marcado por una incierta globalización, Huyssen persigue restablecer el impulso de la tensión entre estética y política como componente fundamental de la teoría cultural y literaria. Este punto resulta crucial y pone de manifiesto la intencionalidad crítica de Huyssen. Su lectura del carácter plural de las prácticas significantes del arte moderno y contemporáneo yuxtapone en una misma constelación crítica a artistas y escritores europeos y latinoamericanos. De este modo, la escultura de Doris Salcedo o la pintura de Guillermo Kuitca proyectadas sobre la tradición estética del alto modernismo adquieren un sentido particular: asincrónico e intempestivo. Resulta evidente que la revisión llevada a cabo por Huyssen apela a las coordenadas geográficas dispuestas por el arte latinoamericano para devolver a la imaginación teórica su potencialidad crítica y política.

En su evaluación sobre el estado actual del pensamiento crítico inserto en una "realidad global mutante" (Modernismo después de la posmodernidad 12), Huyssen insiste en considerar los problemas del modernismo como punto de referencia "para cualquier intento de repensar las viejas cuestiones de la estética y la política para nuestros tiempos" (12). Reinstala, entonces, la preocupación por la forma estética sin renunciar a su capacidad política, para enfocar los procesos culturales implicados en el incierto significante "globalización", hasta ahora abordados desde la economía, la administración política o las tecnologías de la información. Ante este panorama, y advirtiendo la tecnificación de los nuevos medios de comunicación, Huyssen propone rebatir la elevada noción de "literariedad", para colocar en su lugar a unas

10 Cabe señalar la coincidencia y anticipación de Beatriz Sarlo con su ensayo Una modernidad periférica: Buenos Aires 1920 y 1930, donde los problemas estéticos y políticos del alto modernismo se presentan como ejes analíticos. 
textualidades que se diseminan más allá de la "especificidad de los medios artísticos" (30). En consecuencia, la literatura y el arte herederos del alto modernismo cambian radicalmente su fisonomía; en su lugar se instala una trama de experiencias estéticas inasibles desde los parámetros de producción e interpretación típicamente modernos, en los cuales la diferenciación entre productores y público resultaba estable. Coincidiendo en su evaluación con Laddaga, el modelo teórico de Huyssen busca revitalizar la antigua crítica cultural siguiendo una serie de tensiones, cuya primera formulación es la problemática dialéctica global/local. Cabría suponer -quizás, algo adornianamente- que un entorno cultural hiperconectado de consumos culturales homogeneizados resta espacios para la productividad singular. Sin embargo, diversas experiencias -como la proliferación de pequeños sellos musicales y editoriales, el activismo político intervenido por las estrategias de la performance y el arte callejero, las nuevas flexiones para las artes visuales y verbales en soportes digitales- operan una resistencia frente a la pulsión normalizadora. De hecho, estas prácticas estéticas aprovechan los nuevos medios técnicos ya sea como canal de difusión y conexión o como herramientas para el trabajo formal, encontrando nuevas territorialidades en su exploración sensible.

Del mismo modo, la vieja oposición alto/bajo que caracterizó al modernismo durante los siglos XIX y xx, se replantea para enredarse con el problema del valor estético. Al considerar las dimensiones teóricas de esta oposición, Huyssen reintroduce la dialéctica entre la imaginación estética y las aristas de un real que se resiste tanto a la petrificación positivista como al mero juego de lenguajes antirrepresentativos. Si la hibridación, tal como señala García Canclini, caracteriza a los procesos culturales, para Huyssen esos procesos de mestizaje corren el riesgo constante y omnipresente de ser domesticados por un mercado que tiende a homogenizar lo irregular, suprimir sus filos y disrupciones productivas. En su evaluación crítica, el mercado se demuestra como un territorio refractario a la experimentación de la expresión estética y al pensamiento crítico, aunque su voracidad obligue a considerar sus implicancias. En un sentido análogo, cabría considerar las manifestaciones contemporáneas de la administración del poder político - con la singularidad de cada estado-, las cuales parecen adquirir una tendencia marcadamente adversa al pensamiento crítico. La conjunción de estas dos refracciones vuelve a instalar en el presente los reparos expresados por las filosofías de Benjamin y Adorno sobre la cultura administrada y los usos estetizados de la política. Desmarcándose de estas dos polaridades conservadoras, parece surgir, desde Huyssen, una visión -una teoría- de la literatura y el arte como "empresa intempestiva", es decir, fuera del tiempo, o mejor dicho, asincrónica; ${ }^{11}$ de

11 La noción de "asincronía” aparece por primera vez en su ensayo Después de la gran división; punto central de su teoría, permite desactivar la visión de un tiempo histórico lineal y teleológico. En su lugar, la multiplicidad de temporalidades, la presencia del pasado en el presente, las proyecciones desde el presente hacia el futuro y la evidencia fundamental de que los procesos de difusión y transmisión de la cultura conllevan temporalidades múltiples, no siempre coincidentes, plagadas de destiempos y retornos que hacen de esta noción un dispositivo conceptual productivo. 
acuerdo al autor, "esto pude ser también una oportunidad para la literatura. Porque necesitamos un espacio de escritura compleja e imaginativa que pueda reorientarnos en el mundo" (Modernismo después de la posmodernidad 42-3). La apuesta teórica traza un horizonte de acción que esboza un ethos para la escritura literaria y, simultáneamente, un itinerario crítico cuya finalidad es reconsiderar las relaciones entre la estética y los efectos políticos en una sociedad decididamente interconectada y sujeta a los "hechizos de la globalización" (43). La reorientación propuesta por Huyssen implica, entonces, ampliar geografías e hibridar experimentaciones estéticas sin caer en la estandarización de una pluralidad domesticada o en la restauración de un conservadurismo cultural.

Ahora bien, si el pensamiento de Rancière permite visualizar la conformación de la modernidad estética y su devenir histórico, es necesario advertir que esta construcción conceptual se realiza fundamentalmente anclada en experiencias europeas. Las apuestas de Laddaga y Huyssen intentan abordar el estado actual del régimen estético incorporando una perspectiva a la vez global y atenta a las particularidades locales. En este sentido, la obra de crítica de García Canclini aporta esta cartografía una modulación sensible a las articulaciones del pensamiento y la creación latinoamericanas. Las nuevas formas de politización o activismo, la confrontación contra las pervivencias represivas de los estados y la omnipresencia solapada de la violencia forman parte de una calibración singular de las estéticas trazadas desde la realidad de América Latina.

En La sociedad sin relato, García Canclini articula la complejidad del estado actual de la discusión teórica desde un gesto que vuelve a colocar al pensamiento, el arte y la literatura en un mismo plano de problemas. A partir del ensayo borgeano "La muralla y los libros", ${ }^{12}$ considera la experiencia estética contemporánea bajo el signo de la inminencia, esto es, como una posibilidad de sentido imaginativa y proyectual a realizar. Según el autor, los mecanismos antropológicos del arte, su trabajo con la forma y la ficción establecen nuevos pactos de sociabilidad e imaginación crítica no atados a las claves dadas por el relato social dominante. El carácter inminente de las prácticas estéticas implica un horizonte de posibilidad que rehúye el dato duro y cuantificable de la política o la economía. La estética toma la forma de territorio de disidencias y la composición de nuevas relaciones sociales. En este punto, la propuesta de García Canclini elabora conceptos afines tanto a la estética disensual de Rancière como a la estética relacional de Nicolás Bourriaud, aunque enfocada en artistas latinoamericanos como León Ferrari, Teresa Margolles, Carlos Amorales o Alfredo Jarr.

De acuerdo con la perspectiva de García Canclini, frente a una sociedad en la cual proliferan los simulacros -tanto en los medios de información como en política

12 El ensayo de Borges del cual parte García Canclini se incluye en Otras inquisiciones: "La música, los estados de felicidad, la mitología, las caras trabajadas por el tiempo, ciertos crepúsculos y ciertos lugares, quieren decirnos algo, o algo dijeron que no hubiéramos debido perder, o están por decir algo; esta inminencia de una revelación que no se produce, es, quizá, el hecho estético" (635). 
y economía-, el arte propone un modo de disensual de acercamiento a lo real, aunque alejándose tanto de la antigua propensión vanguardista a la transgresión, como de los discursos teóricos deconstructivos que pregonan la incapacidad de su captura. Esta reelaboración de lo real produce una inestabilidad que conlleva la problematización de los límites y lenguajes de las prácticas artísticas, y conduce hacia un replanteo de su propia autonomía. Las constantes fluctuaciones que el arte y la literatura proponen en su diálogo con el mundo se hacen eco, según el ensayista, en los debates sobre la "posautonomía" que desde el artículo de Víctor Tupitsyn, titulado "Post-autonomous Art” (2004) llega hasta las literaturas posautónomas de Josefina Ludmer (2010). De acuerdo con García Canclini, la posautonomía envuelve una serie de desplazamientos que reorganizan el territorio de lo artístico para conducirlo hacia nuevos espacios, nuevas relaciones e identidades que parecen diluir la forma estética resistente y negativa del alto modernismo. La visión de un arte y una literatura posautónomas implican, entonces, no el fin de un discurso y una práctica, sino su dispersión e intersección con otras esferas del mundo común. El efecto, para la estética, no es su supresión sino, por el contrario, la diseminación constante de sus modalidades de trabajo y sentido. Cabría pensar que el prefijo pos -cargado con una significación de linealidad historicista- quizás no sea el adecuado para designar el estado actual del arte, y en su lugar establecer el designado por Rancière (en diálogo polémico con Adorno) como caracterización general del régimen estético, esto es, una verdadera heteronomía. ${ }^{13}$ En consecuencia, la estética y las diversas formas del arte en el presente se disponen no como un "campo normativo", sino como un "ámbito abierto" que reúne formas, representaciones y experiencias las cuales componen un territorio de "posibilidades en un mundo sin normas preestablecidas" (García Canclini 39). Consecuente con esta apertura, los recorridos de García Canclini se asumen "indisciplinados”, responden polémicamente tanto a los "muros académicos" como a los "marcos" artísticos y teóricos en un intento por trascenderlos.

\section{Coda}

Al considerar las prácticas artísticas contemporáneas y los modos de inteligibilidad crítica, es posible advertir un signo común para la estética novosecular; ya sea a través de su carácter "disensual" (Rancière) o "relacional" (Bourriaud), desde la "emergencia” (Laddaga) o lo "intempestivo" (Huyssen) se postulan modulaciones compartidas

13 Sostiene García Canclini: "La reelaboración de la teoría estética y del análisis crítico necesita hacerse cargo de las pertenencias múltiples y las localizaciones móviles de actores que exhiben el arte a la vez en los museos, los medios, el ciberespacio y las calles, que mantienen cierta voluntad de forma tanto en los espacios 'propios' como en otras zonas donde las imágenes se hacen visibles y las escrituras legibles bajo una normatividad heterónoma. La tarea no es renunciar a la diferencia de ciertos 'creadores' y 'obras', sino percibir cómo sus autores entran en conflicto y negocian su sentido en los intercambios con las industrias culturales o en medio del pragmatismo social” (53). 
que asumen su problemática relación con el mundo. Decididamente, la estética se emplaza en lo real para configurarlo como escena espectacular, promesa de sentido o insinuación política fuera de los datos duros de la lógica pragmática, la administración del poder o la economía. Según García Canclini: "Las obras no simplemente suspenden la realidad; se sitúan en un momento previo, cuando lo real es posible, cuando todavía no se malogró. Tratan los hechos como acontecimientos que están a punto de ser" (La sociedad sin relato 12); de ahí su carácter “inminente”. Por supuesto, la inminencia estética es un modo singular de imaginar un régimen abierto en el cual se materializa la organización y visibilidad de unos cuerpos, unas voces y sus formas.

Según escribieran Deleuze y Guattari en ¿Qué es la filosofía? (1991), el pueblo que todavía falta y el acontecimiento estético por venir son modos afines para decir algo evidente: estética y política se yuxtaponen. En consonancia, frente al discurso del fin, la negatividad radical o la añoranza del saber letrado del alto modernismo, no es la literatura ni las experimentaciones estéticas las que mueren, sino un marco de inteligibilidad y referencia. Frente a ese panorama, se impone necesario advertir las mutaciones de una sociedad sin un relato a priori, visualizada como un tejido de subjetividades y representaciones (verbales, visuales, transdiscursivas) predispuesto a la irrupción de unas formas de vida por imaginar. La exploración estética sería una pregunta por esas formas, por sus modos de organización y reordenamiento del material sensible; y, al mismo tiempo, una producción de sentido que intenta comprender su dispersión en una territorialidad común.

Si las formas del arte y la estética se entienden intempestivas, tensionadas por asincronías e imaginarios a realizar, entonces el trabajo crítico que traza su visibilidad no puede sustraerse de esta condición. Se impone plantear ya no explicaciones e interpretaciones determinantes, sino itinerarios y cartografías inconclusas construidas como ecologías culturales y concebidas desde un dialogismo radical. Quizás, la tarea de la estética en el nuevo siglo sea la de asumir (y leer retrospectivamente) su politicidad, a fin de elaborar una imaginación crítica de las formas sensibles, sin renunciar a convertirse en una exploración sobre la materia elusiva y cambiante de su presente. En ese itinerario, tal vez, pueda escribir una historia junto al arte sin borrar "el recuerdo del sufrimiento acumulado" (Adorno 339).

\section{Referencias}

Adorno, Theodor W. Teoría estética. Madrid: Hyspamerica, 1983. Impreso.

Badiou, Alain. Pequeño manual de inestética. Buenos Aires: Prometeo, 2008. Impreso. Barthes, Roland. El placer del texto y Lección inaugural: De la cátedra de Semiología Literaria del Collège de France. Buenos Aires: Siglo xxI, 2014. Impreso.

Benjamin, Walter. "El autor como productor". Tentativas sobre Brecht. Iluminaciones III. Madrid: Taurus, 1998. 117-134. Impreso. 
Borges, Jorge Luis. "La muralla y los libros". Obras Completas (1923-1972). Buenos Aires: Emecé, 1974. 633-635. Impreso.

Bourriaud, Nicolás. Estética relacional. Buenos Aires: Adriana Hidalgo, 2008. Impreso. Bürger, Peter. Teoría de la vanguardia. Buenos Aires: Las Cuarenta, 2010. Impreso.

Deleuze, Gilles y Guattari, Félix. ¿Qué es la filosofía?. Barcelona: Anagrama, 2009 [1991]. Impreso.

Ferrater Mora, José. Diccionario de filosofía. Buenos Aires: Sudamericana, 1965. Impreso. Foucault, Michel. “¿Qué es la ilustración?”. Actual 28 (1994). <http://www.saber.ula. ve/bitstream/123456789/15889/1/davila-que-es-la-ilustracion.pdf $>$. Fecha de ingreso: 13 de marzo de 2017. Web.

García Canclini, Néstor. La sociedad sin relato. Antropología y estética de la inminencia. México: Katz, 2010. Impreso.

Huyssen, Andreas. Después de la gran división: modernismo cultura de masas, posmodernismo. Buenos Aires: Adriana Hidalgo, 2006. Impreso.

---. Modernismo después de la posmodernidad. Barcelona: Gedisa, 2010. Impreso.

Laddaga, Reinaldo. Estéticas de la emergencia. Buenos Aires: Adriana Hidalgo, 2006. Impreso.

---. Espectáculos de realidad: ensayo sobre la narrativa latinoamericana de las últimas dos décadas. Rosario: Beatriz Viterbo, 2007. Impreso.

Ludmer, Josefina. Aquí América Latina. Buenos Aires: Eterna Cadencia, 2010. Impreso. Rancière, Jacques. El reparto de lo sensible. Santiago de Chile: LOM, 2009. Impreso.

---. La palabra muda: ensayo sobre las contradicciones de la literatura. Buenos Aires: Eterna Cadencia, 2009. Impreso.

---. El malestar en la estética. Buenos Aires: Capital Intelectual, 2011. Impreso.

Sarlo, Beatriz. Una modernidad periférica: Buenos Aires 1920-1930. Buenos Aires: Nueva Visión, 2003 [1988]. Impreso.

Tupitsyn, Víctor. "Post-autonomous art". Third Text. Critical Perspective on Contemporary Art 18.3 (2004). 273-282. Impreso.

Williams, Raymond. Marxismo y literatura. Buenos Aires: Las Cuarenta, 2009. Impreso.

Recibido: 13 marzo 2017

Aceptado: 3 octubre 2017 